\section{Proceedia}

COMPDYN 2021 Computational Methods in Structural Dynamics and Earthquake Engineering M. Papadrakakis, M. Fragiadakis (eds.) Streamed from Athens, Greece, 28 - 30 June 2021

\title{
LARGE-DISPLACEMENT RESPONSE OF UNREINFORCED MASONRY STRUCTURES: COMPARISON BETWEEN ANALYTICAL SOLUTIONS AND DEM MODELS INCLUDING OPEN-SOURCE SOFTWARE
}

\author{
Igor Bouckaert ${ }^{1 *}$, Michele Godio ${ }^{2}$, João Pacheco de Almeida ${ }^{1}$ \\ ${ }^{1}$ Institute of Mechanics, Materials and Civil Engineering, UCLouvain \\ Louvain-la-Neuve, Belgium \\ \{igor.bouckaert, joao.almieda\}@uclouvain.be \\ ${ }^{2}$ RISE Research Institutes of Sweden \\ Brinellgatan 4, 50462 Borås, Sweden \\ michele.godio@ri.se
}

\begin{abstract}
Unreinforced masonry (URM) has been the most widespread construction material for centuries and is widely used in many countries. Accurate numerical models for this material are required when designing new structures, and, even more importantly, for assessing or renovating the existing stock. However, an accurate modelling of URM structures remains a challenge due to its highly non-linear mechanical behaviour involving, among other features, large out-of-plane displacements, the variability of the material properties, and the influence of construction details. The discrete element method (DEM), for which applications to masonry structures appeared in the 1990s, has gained in popularity due to its capacity to accurately capture masonry-specific phenomena; in particular, as it represents the structure as an assembly of distinct blocks, deformations are concentrated at the interfaces with low or zero tension strength, and the effect of large displacements. Unfortunately, the majority of computer programs for structural analysis based on the DEM are proprietary software, which limits its spread among practitioners and researchers. The aim of this work is to evaluate the open-source software package LMGC90, which implements the Non-Smooth Contact Dynamics Method, as a tool for modelling masonry structures.
\end{abstract}

Keywords: Masonry, Structural Dynamics, Discrete Element Methods, Open source 


\section{INTRODUCTION}

Recently, the region of Wallonia (Belgium), along with the neighbouring parts of France, Germany and Holland, was indicated as one of the locations in Europe with potential for largest economic losses, because of their very large exposure and vulnerability to earthquakes [3]. Recent exposure studies have shown that the most earthquake-prone cities in Belgium have an absolutely predominant stock of URM buildings $[4,13]$. One example is the city of Liège struck by an earthquake in 1983 damaging around 16'000 houses - for which $95 \%$ of their buildings are in masonry [2]. A good understanding of the structural behaviour of typical Belgian masonry houses is therefore required to predict and best prevent the occurrence of potential damage in future low- to medium-intensity earthquakes.

In this paper, we investigate the open source software $L M G C 90$ [12] as a tool for modeling masonry structures subjected to earthquakes. This software was originally developed for spherical elements, simulating rapid granular flows [14]. Eventually, it was adapted to polyhedral elements and its relevance for URM modeling has been growing ever since [11]. This software has been used to study the seismic behaviour of historical masonry structures such as the Roman amphitheatre in Nimes [15], a medieval church in Portuno [10], or the reassessment of a wall in the Prince of Wales's Fort [9]. In the last decade, some specific features relative to the modeling of URM buildings have been added to $L M G C 90$ and the software becomes more and more interesting for the URM community [16]. The aim of this paper is to evaluate the suitability of the software for masonry modeling. The results of the examples presented in the current study are benchmarked against analytical solutions and numerical results obtained with another wellknown proprietary DEM software, namely UDEC [5,6]. The examples presented in this study address several issues encountered when modeling the large-displacement response of masonry structures subjected to earthquakes, like the effect of rocking, contact stiffness and imperfections between the blocks. Two benchmark problems are presented and discussed in this paper. the first one adresses the rocking response of masonry columns, and the second one adresses the in-plane behaviour of masonry panels. In Section 2, a masonry column and a masonry arch are submitted to a horizontal impulse acceleration at the base and the failure domain is computed in terms of impulse amplitude and duration. The results are compared with those of a UDEC model reported in the literature [7]. In Section 3, the in-plane behaviour of a series of panels is analysed through up-to-collapse quasi-static simulations. The results are shown in terms of collapse mechanism and force capacity for each wall and compared with existing solutions extracted from the literature [8] as well as with the results of ad-hoc UDEC simulations.

\section{RESPONSE OF COLUMNS AND ARCHES TO IMPULSE BASE ACCELERATION}

\subsection{Description of the benchmark}

The aim of this benchmark is to explore the ability of $L M G C 90$ to capture the rocking mechanism of masonry structures. Moreover, the construction of non-convex shapes - with the associated difficulties of contact determination - is addressed in the second part of the example.

Firstly, the dynamic behaviour of a URM column (dimensions shown in Figure 1a) subjected to a two-sided horizontal base impulse acceleration represented in Figure 2 is analysed. A parametric study is carried out on the column by increasing the acceleration amplitude $a$ for a range of impulse duration $t_{p}$ varying between 0.1 and $1.0 \mathrm{~s}$. This is done in order to obtain the failure domain of the column, i.e. the couples of values $\left(a, t_{p}\right)$ which lead to the collapse of the column. The column modelled in this example is inspired from the $9^{\text {th }}$ column of the eastern 


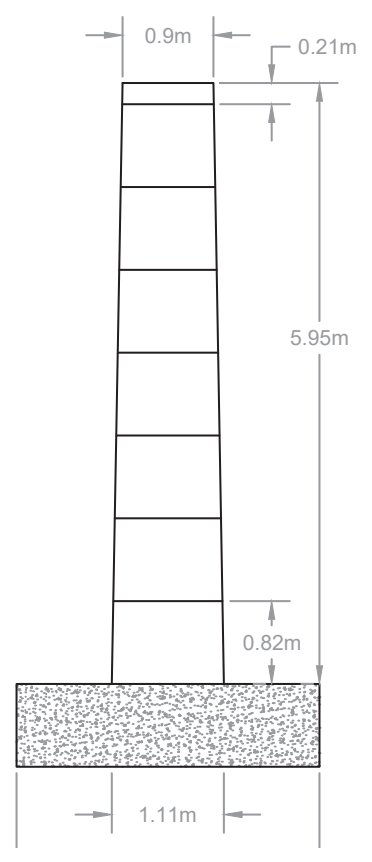

(a)

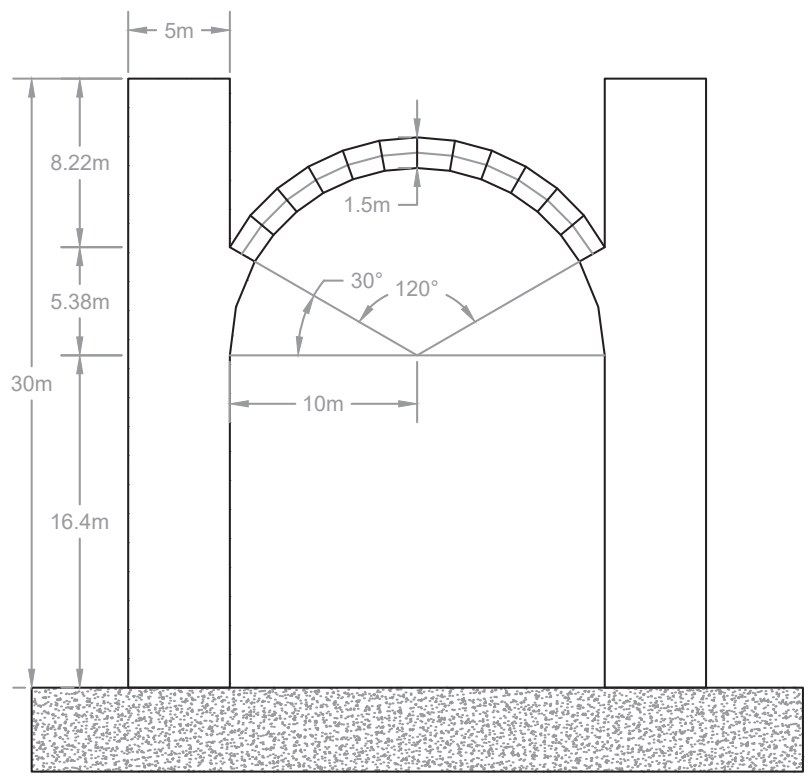

(b)

Figure 1: Geometry of the analysed column (a) and arch (b)

\section{Step impulse}

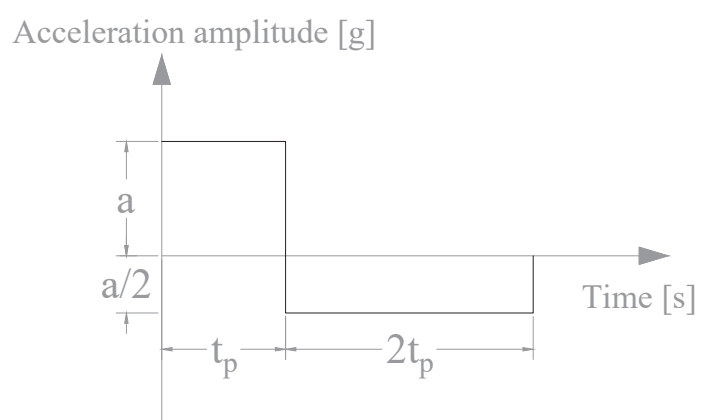

Figure 2: Acceleration step impulse applied to the base of the column [7]

flank of the temple of Apollo at Bassae, Greece. It is composed of 8 drums and has a total height of $5.95 \mathrm{~m}$, a base width of $1.11 \mathrm{~m}$ and a top width of $0.9 \mathrm{~m}$. The model implemented in $L M G C 90$ is in two dimensions with rigid blocks with a density of $2620 \mathrm{~kg} / \mathrm{m}^{3}$. The contact between the blocks is a Coulomb friction law with a friction angle of $35^{\circ}$, which is equivalent to a coefficient of friction $\mu=0.7$. The simulation is run for $20 \mathrm{~s}$ in order to observe the response of the column after the application of the step impulse. The failure domain obtained with this model is compared with the one obtained by the implementation of the same problem using UDEC, by Dimitri et al. [7]. The UDEC model is implemented without damping while the damping model used in $L M G C 90$ is the default model of the program. The definition of the damping model and damping parameters in $L M G C 90$ will be explored in future studies.

A similar study is then carried out for a circular arch supported on buttresses. The dimen- 
sions of the problem are shown in Figure 1b. The arch consists of 12 voussoirs, while each buttress is modelled as one monolithic block. The base of the buttresses is subjected to the same two-sided impulse acceleration used in the previous example. In particular, the acceleration is progressively increased until the failure of the arch is attained. Moreover, the position of the hinges that form in the collapse mechanism at specific values of $a$ and $t_{p}$ is compared with the results obtained with UDEC [7].

\subsection{Results and discussion}

The results obtained with $L M G C 90$ are summarised in this section. The plots were generated with the open-source multiple-platform application for interactive scientific visualisation ParaView [1].

Figure 3a shows that the failure domain obtained with the model implemented in $L M G C 90$ agrees well with the failure domain obtained with $U D E C$ in the work by Dimitri et al. [7]. As the value of $t_{p}$ increases, the acceleration amplitude causing the collapse of the column comes closer to the value of $0.19 \mathrm{~g}$, which is the magnitude necessary to put the column in motion according to the equilibrium static analysis. Acceleration amplitudes below that value are not going to initiate any rocking or sliding of the column [7]. The graph also hints at a change in the failure mode at around $t_{p}=0.34 \mathrm{~s}$ : below that value, the columns tilts to the left and only a portion of the blocks is involved in the failure mechanism, whereas the full column tilts to the right for impulse duration above this threshold value. The failure modes obtained at $t_{p}=0.2 \mathrm{~s}$ and $t_{p}=0.8 \mathrm{~s}$ are displayed in Figures $3 \mathrm{~b}$ and $3 \mathrm{c}$. This could be explained by the fact that, below this threshold value, the column collapses during the first part of the impulse (positive acceleration $a$ ) whereas for longer impulses the collapse occurs in the second part of the impulse (negative acceleration $a / 2$ ). In addition, for shorter impulses, higher rocking 'modes' are activated. As the impulse duration decreases, the results from $L M G C 90$ and from Dimitri et al. [7] seem to match a little bit less. This difference is probably due to definition of the damping parameters in $L M G C 90$, which will be analysed in future studies.

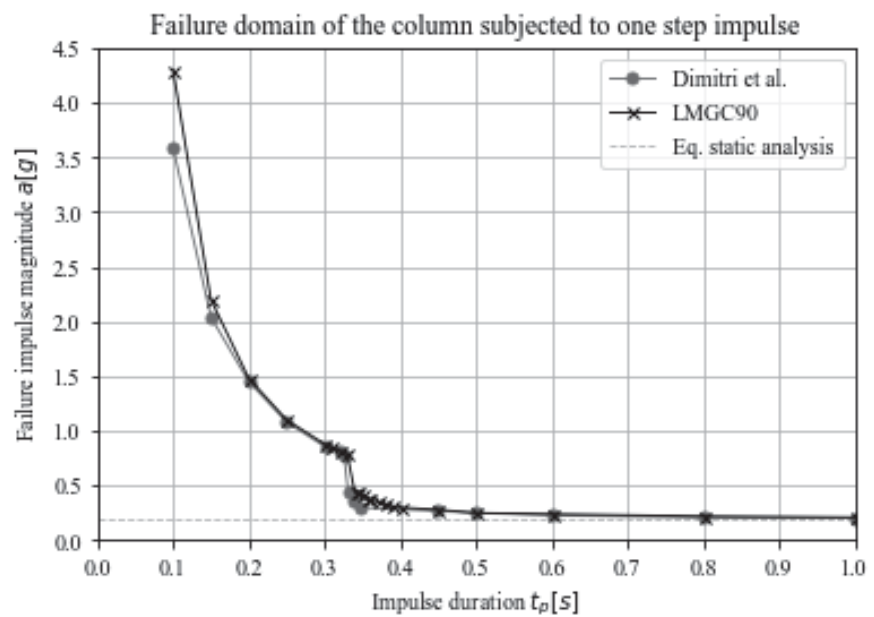

(a)

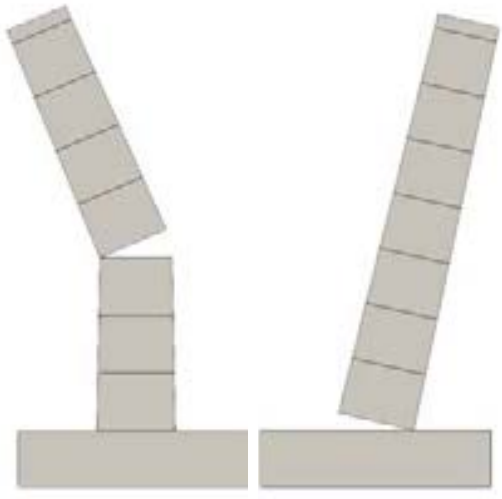

(c)

(b)

Figure 3: (a) Failure domain of the column subjected to the step impulse (b) Failure mode at $t_{p}=0.2 \mathrm{~s}$ and (c) Failure mode at $t_{p}=0.8 \mathrm{~s}$

Figure 4 shows the results obtained for the arch of Figure 1b. Also in this case the results 
obtained with $L M G C 90$ match very satisfactorily those obtained by Dimitri et al. [7]. Moreover, the collapse mechanisms produced by both software at two different acceleration amplitudes were compared and are in good agreement in terms of the position and number of hinges that form at collapse, see Figures $6 a$ and $6 b$.

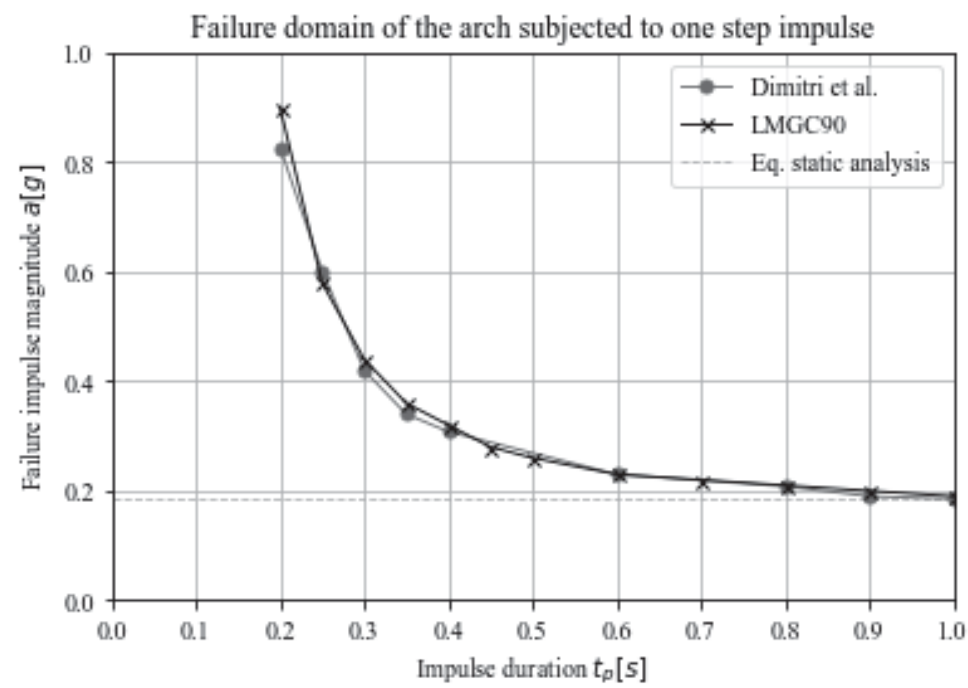

Figure 4: Failure domain of the circular arch subjected to the step impulse

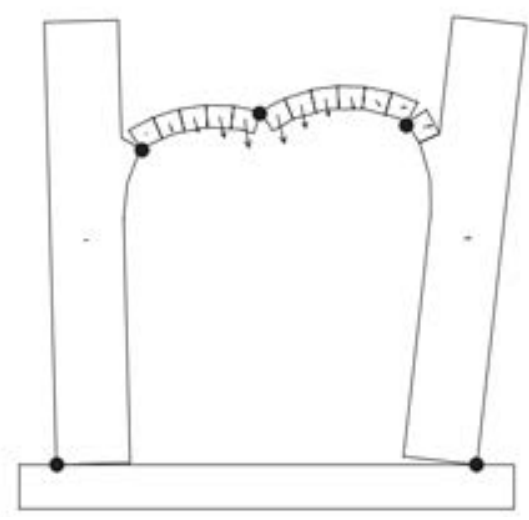

(a)

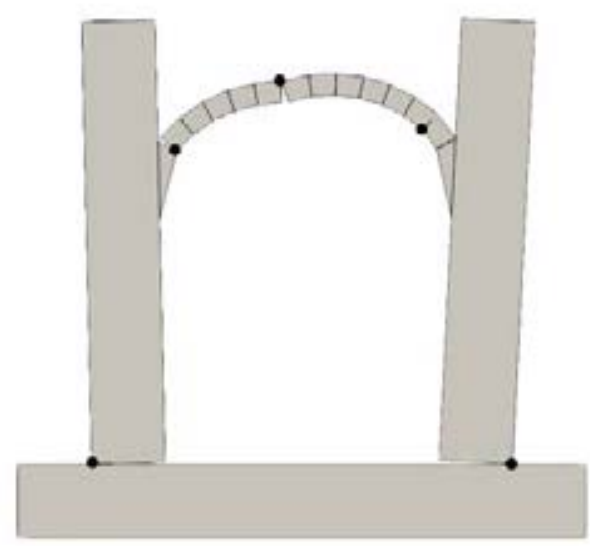

(b)

Figure 5: Failure mode of the arch at $t_{p}=0.2 \mathrm{~s}, a=0.82 \mathrm{~g}$, from (a) UDEC [7] and (b) LMGC90 


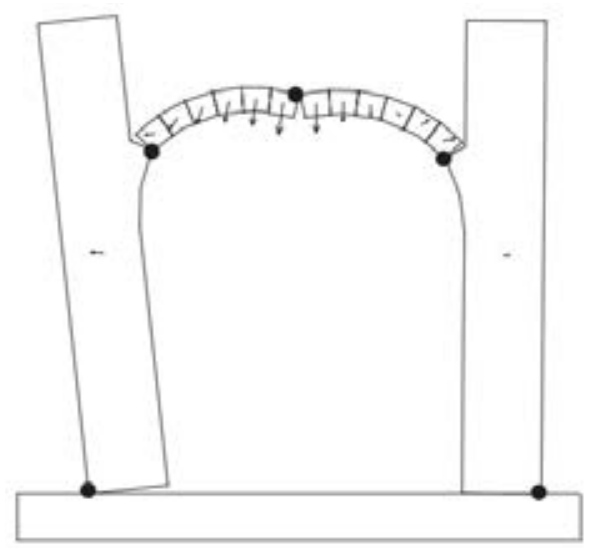

(a)

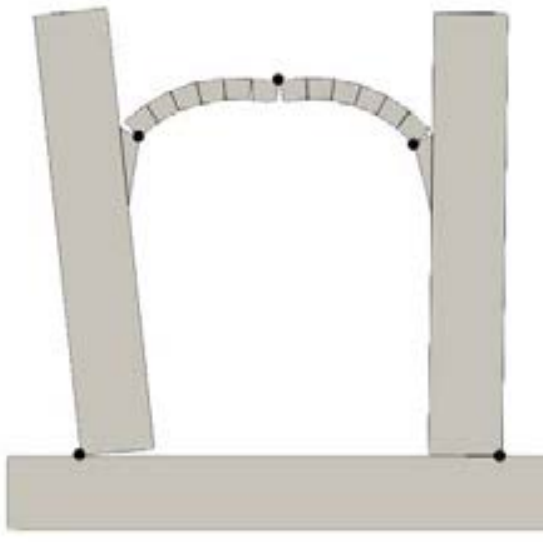

(b)

Figure 6: Failure mode of the arch at $t_{p}=1 \mathrm{~s}, a=0.2 \mathrm{~g}$, from (a) $U D E C$ [7] and (b) $L M G C 90$

\section{IN-PLANE BEHAVIOUR OF MASONRY WALLS SUBJECTED TO STATIC LAT- ERAL LOAD}

\subsection{Description of the benchmark}

In this benchmark, quasi-static analyses are performed on a series of six wall configurations. Each wall is composed of bricks of size $0.4 \mathrm{~m} \times 0.175 \mathrm{~m}$ with sharp or rounded edges, as depicted in Figure 7. The walls have different geometries, four of which include openings, as depicted in Figures 8 to 13. During the analysis, each block is subjected to its self-weight $W$, being the unit weight of the blocks equal to $10 \mathrm{kN} / \mathrm{m}^{3}$, and to a horizontal force $\alpha W$ applied at its centre of gravity (Figure 7a). This configuration allows the seismic loading to be simulated as an equivalent static lateral force distribution proportional to the blocks mass [8].

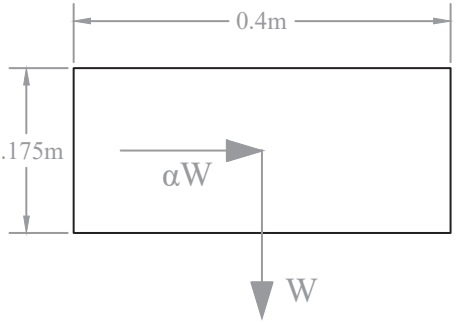

(a)
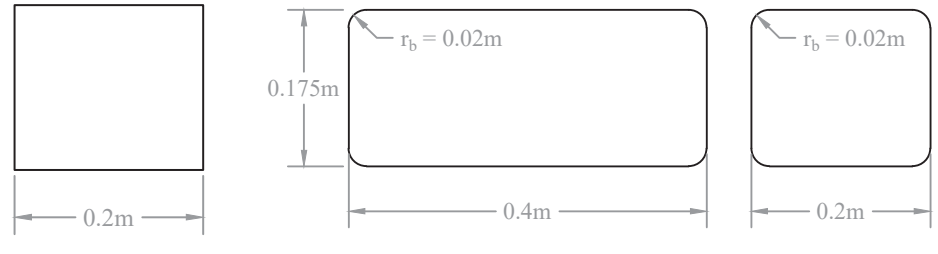

(b)

Figure 7: (a) Block and half-block with sharp edges (applied forces shown on the full block) for comparison with [8] (b) Block and half-block with rounded edges for comparison with UDEC

The objective of this example is to find the maximal in-plane capacity of the wall, which, according to the load pattern described above, is expressed in terms of maximum collapse load multiplier $\alpha_{\max }$ and corresponds to the maximum value of $\alpha$ that the wall can sustain. 


\subsection{Comparison between solutions from limit analysis and $L M G C 90$}

First, the benchmark is implemented in $L M G C 90$ with rigid blocks with sharp edges as shown in Figure 7a. The contact law between the blocks is defined by a rigid-plastic law, and failure between the blocks is described by a Coulomb friction criterion with friction coefficient $\mu=0.65$ and zero tensile strength. During the first $10 \mathrm{~s}$ of the simulation, the bricks are only subjected to their self-weight. Next, the value of the load multiplier $\alpha$ is linearly increased at a rate of $5 \times 10^{-4} / \mathrm{s}$ which is assumed to be low enough to keep the system in quasi-static conditions until the collapse mechanism forms. The value of $\alpha_{\max }$ selected as the collapse load multiplier is the maximal horizontal reaction observed at the support divided by the total weight of the wall. Indeed, a decrease in the horizontal reaction while the total applied horizontal force keeps increasing linearly can only mean that equilibrium is no longer satisfied and that part of the applied horizontal force is converted into kinetic energy.
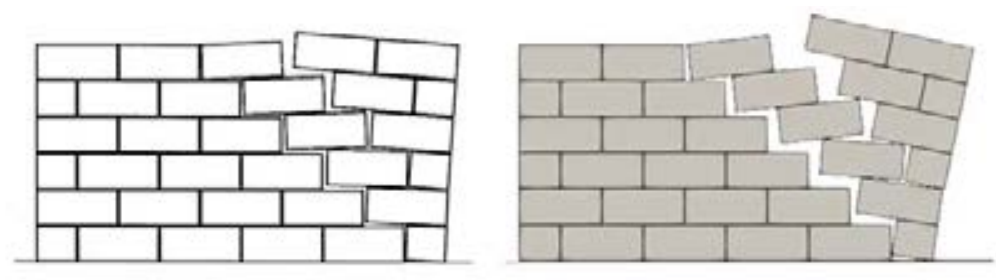

Figure 8: Mechanism of wall 1 (sharp edges) from limit analysis [8] (left) and LMGC90 (right)
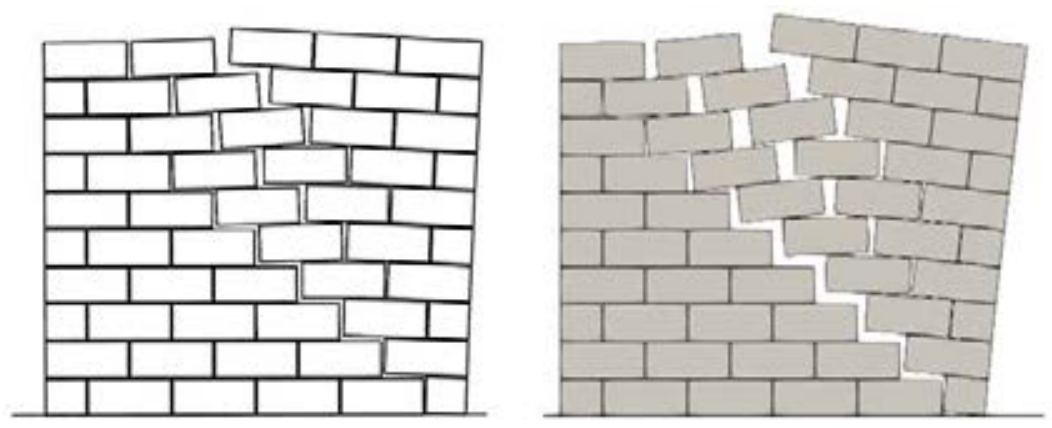

Figure 9: Mechanism of wall 2 (sharp edges) from limit analysis [8] (left) and LMGC90 (right)
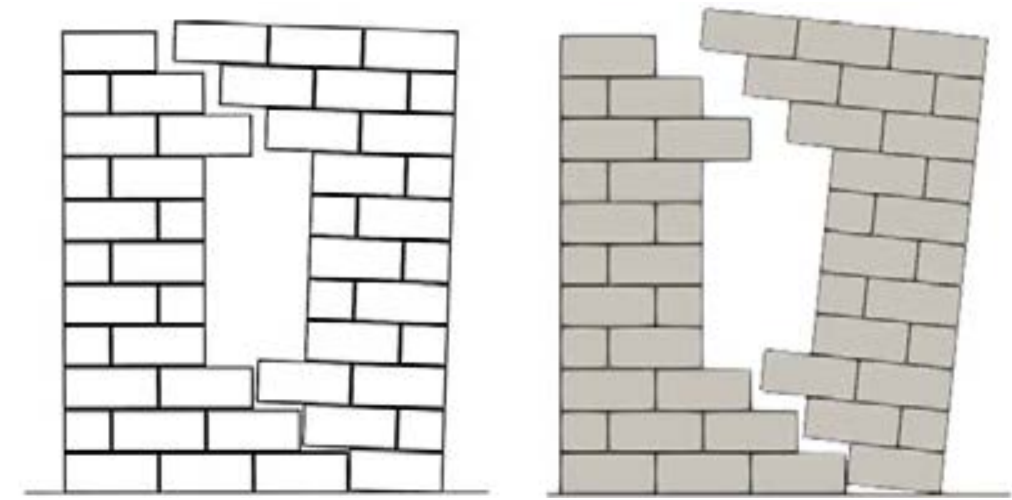

Figure 10: Mechanism of wall 3 (sharp edges) from limit analysis [8] (left) and $L M G C 90$ (right) 

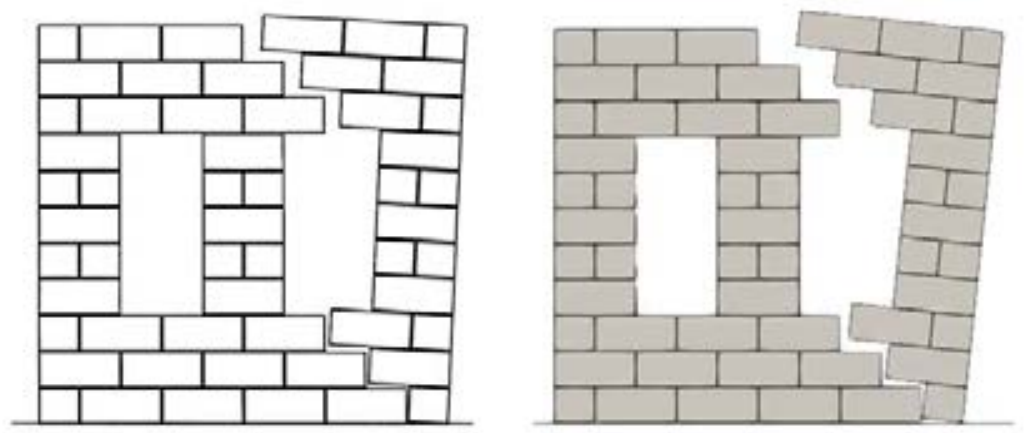

Figure 11: Mechanism of wall 4 (sharp edges) from limit analysis [8] (left) and LMGC90 (right)
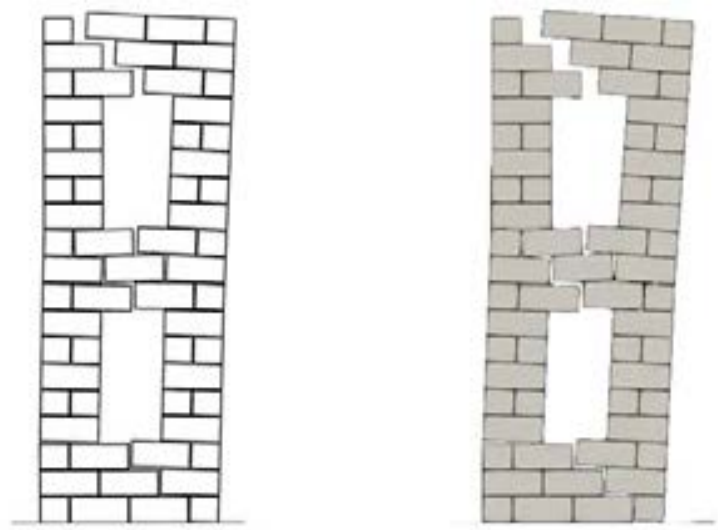

Figure 12: Mechanism of wall 5 (sharp edges) from limit analysis [8] (left) and LMGC90 (right)

The values of $\alpha_{\max }$ are compared with the collapse load multipliers calculated by means of a limit analysis of the walls formulated as a special optimisation problem known as Mathematical Program with Equilibrium Constraints (MPEC) described by Ferris and Tin-Loi [8]. The results are summarized in Table 1. The collapse mechanisms obtained with LMGC90 are compared with those shown by Ferris and Tin-Loi [8] in Figures 8 to 13. The figures obtained by LMGC90 are plotted when the displacement of the upper right corner of the wall was equal to $0.2 \mathrm{~m}$. The value of this displacement is not specified in [8] but the figures clearly display very similar cracking patterns.

\begin{tabular}{|c|c|c|c|}
\hline & \multicolumn{2}{|c|}{$\begin{array}{c}\alpha_{\max } \\
\text { Sharp edges }\end{array}$} & \multirow[t]{2}{*}{$\%$ Error } \\
\hline & Ferris [8] & $L M G C 90$ & \\
\hline Wall 1 & 0.643 & 0.640 & -0.5 \\
\hline Wall 2 & 0.564 & 0.565 & +0.2 \\
\hline Wall 3 & 0.359 & 0.358 & +0.3 \\
\hline Wall 4 & 0.264 & 0.266 & +0.8 \\
\hline Wall 5 & 0.216 & 0.216 & +0.0 \\
\hline Wall 6 & 0.297 & 0.295 & -0.7 \\
\hline
\end{tabular}

Table 1: Collapse load multipliers computed in [8] and with LMGC90

The results obtained with $L M G C 90$ are very close to the ones obtained by limit analysis [8], both in terms of collapse load multiplier (with a maximal difference of $0.8 \%$ ) and in terms of 

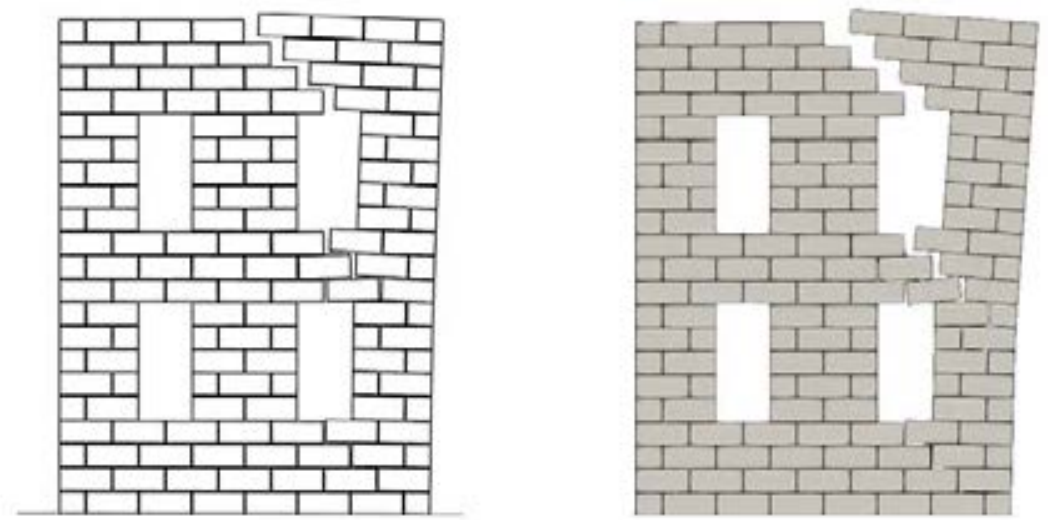

Figure 13: Mechanism of wall 6 (sharp edges) from limit analysis [8] (left) and LMGC90 (right)

collapse mechanism.

\subsection{Comparison between solutions from $U D E C$ and $L M G C 90$}

Since neither the limit analysis carried out by Ferris and Tin-Loi [8], neither the LMGC90 implementation described above take into account any axial stiffness of the bed and head joints, the deformations of the wall before reaching collapse will be zero. Another model has been implemented in two different DEM software, the proprietary software UDEC and the aforementioned open source software $L M G C 90$. This was also done in order to consider the effect of imperfections in the brick corners. This is assumed to be closer to reality than the implementation in section 3.2 where contact was perfectly plastic and blocks had sharp corners.

The bricks implemented in both software are rigid, 2D and have the same dimensions as previously but this time the corners are rounded with a rounding radius $r_{b}$ of $0.02 \mathrm{~m}$, as shown in Figure 7b. Moreover, the contact law is different than in Section 3.2 in order to take into account the stiffness of the joints. In $U D E C$, the user can define the friction coefficient between the blocks ( $\mu=0.65$, as previously), the normal stiffness which was set to $k_{n}=10^{8} \mathrm{~Pa} / \mathrm{m}$, the dilatancy angle and the tangential stiffness. Regarding the two latter parameters, since $L M G C 90$ does not allow to define a tangential stiffness nor a dilatancy angle, those parameters have been set to a very high value and to zero, respectively, to allow a valid comparison with the model implemented in $L M G C 90$. Therefore, in the UDEC model $k_{t}=10^{14} \mathrm{~Pa} / \mathrm{m}$ and $\psi=0^{\circ}$. Since the axial stiffness parameter $K_{n}$ defined in $L M G C 90$ must be expressed in $\mathrm{N} / \mathrm{m}$, the contact stiffness from the model implemented in $U D E C$ must be multiplied by the surface associated to each contact point, namely $0.1 \mathrm{~m}^{2}$ for the bed joints ( 4 contact points for each brick's bed joint) and $0.0875 \mathrm{~m}^{2}$ for the head joints ( 2 contact points for each brick's head joint).

Table 2 summarises the results obtained for the six walls with rounded blocks, both with $U D E C$ and $L M G C 90$. The collapse load multiplier of the walls with rounded edges is a little lower than its equivalent with sharp edges. 


\begin{tabular}{|c|c|c|c|c|c|}
\hline & \multicolumn{2}{|c|}{$\begin{array}{c}\alpha_{\max } \\
\text { Rounded edges }\end{array}$} & \multirow[t]{2}{*}{$\%$ Error } & \multirow[t]{2}{*}{ Sharp edges [8] } & \multirow{2}{*}{$\begin{array}{l}\% \text { Difference between } \\
\text { sharp and rounded edges }\end{array}$} \\
\hline & UDEC & $L M G C 90$ & & & \\
\hline Wall 1 & 0577 & 0.578 & +0.2 & 0.643 & -10.1 \\
\hline Wall 2 & 0.495 & 0.512 & +3.46 & 0.564 & -9.2 \\
\hline Wall 3 & 0.325 & 0.321 & -1.24 & 0.359 & -10.6 \\
\hline Wall 4 & 0.236 & 0.242 & +2.7 & 0.264 & -8.3 \\
\hline Wall 5 & 0.157 & 0.175 & +11.2 & 0.216 & -19 \\
\hline Wall 6 & 0.219 & 0.216 & +1.6 & 0.297 & -27.2 \\
\hline
\end{tabular}

Table 2: Collapse load multipliers computed with UDEC and LMGC90
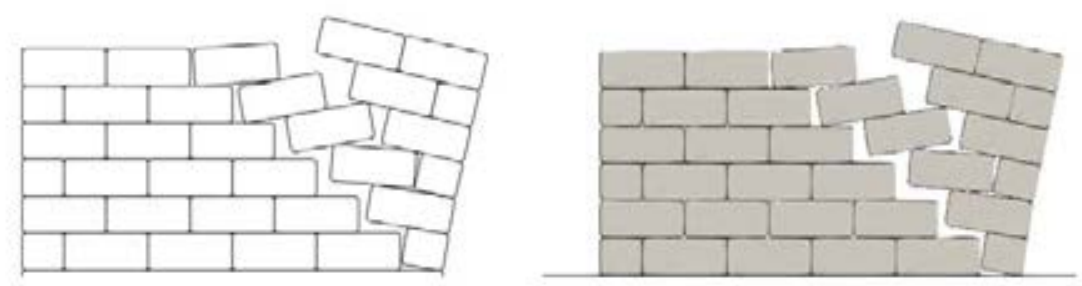

Figure 14: Mechanism of wall 1 (rounded edges) from $U D E C$ (left) and $L M G C 90$ (right)
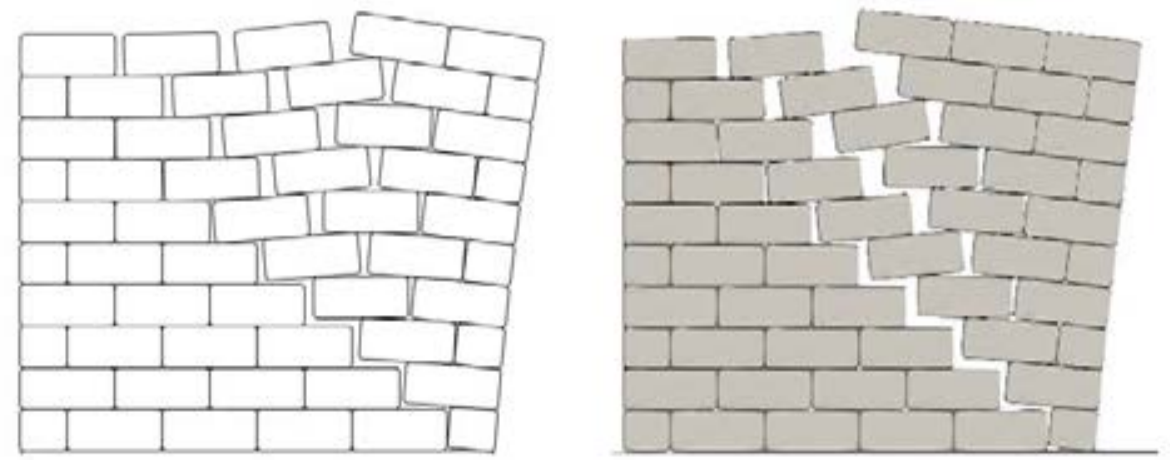

Figure 15: Mechanism of wall 2 (rounded edges) from UDEC (left) and $L M G C 90$
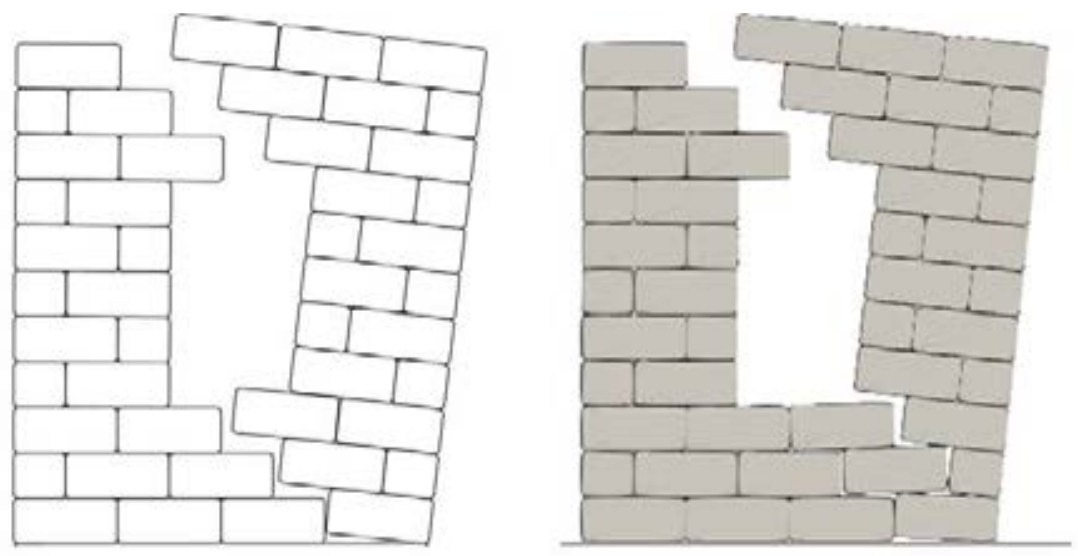

Figure 16: Mechanism of wall 3 (rounded edges) from UDEC (left) and $L M G C 90$ 

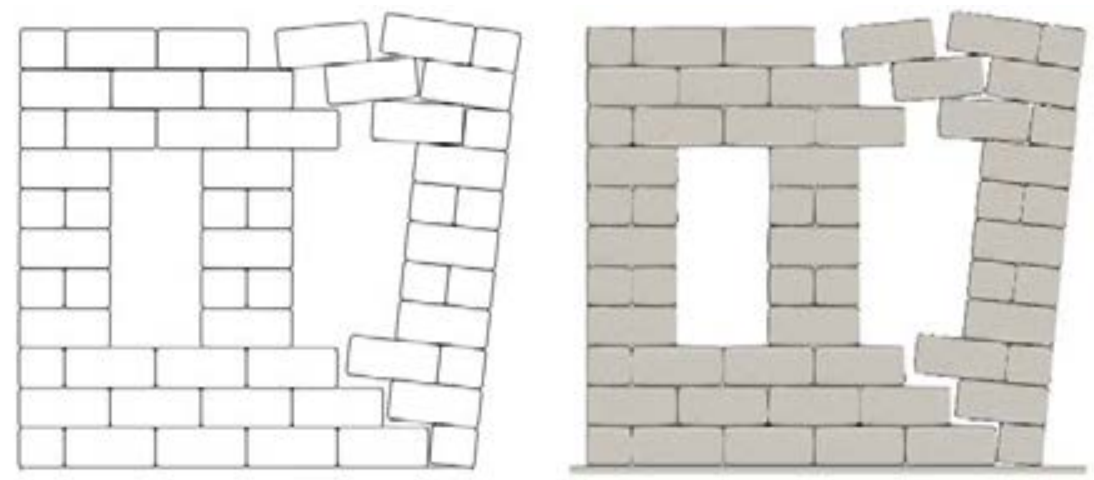

Figure 17: Mechanism of wall 4 (rounded edges) from UDEC (left) and LMGC90
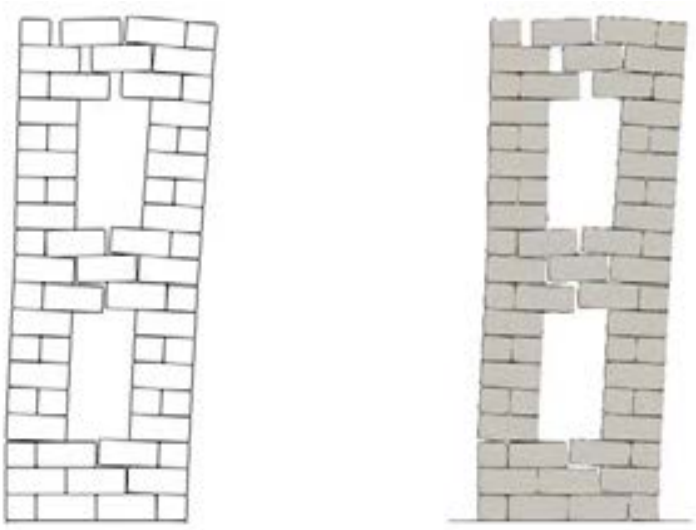

Figure 18: Mechanism of wall 5 (rounded edges) from UDEC (left) and LMGC90
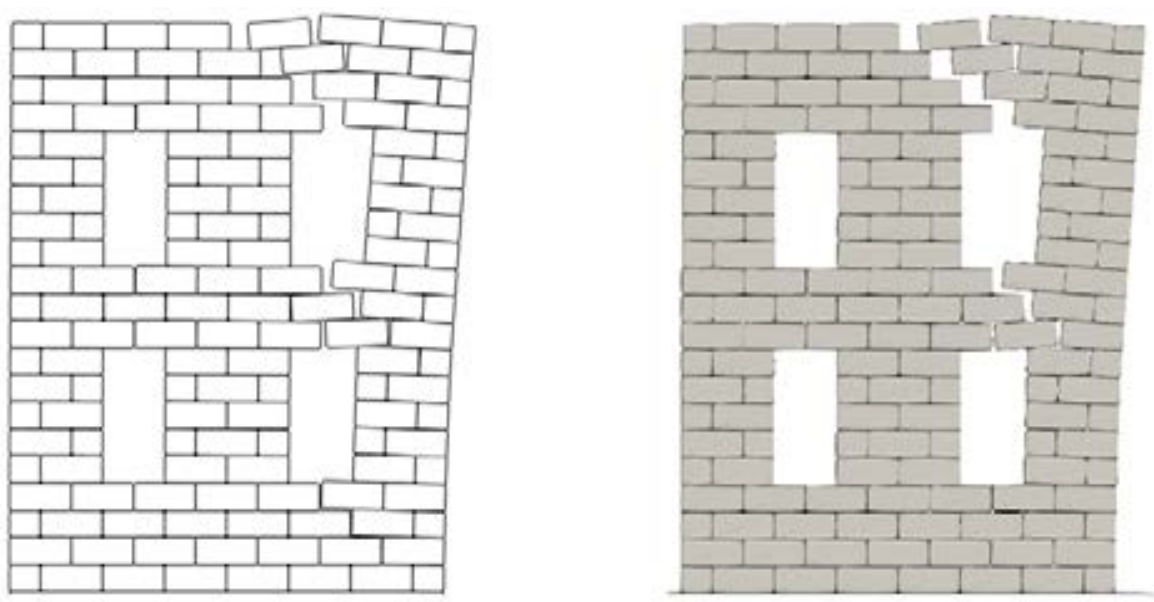

Figure 19: Mechanism of wall 6 (rounded edges) from UDEC (left) and $L M G C 90$

The collapse mechanisms of the six walls with rounded edges are displayed in Figures 14 to 19. Both for UDEC and LMGC90, the collapse mechanism is displayed when the upper right corner of the upper right brick reaches a displacement of $0.2 \mathrm{~m}$. In general, the two solutions are very close to each other in terms of collapse mechanisms. The exception is in the mechanism 
of the third wall, where a bigger macro-block detaches from the structure in the mechanism obtained in $U D E C$, see Figure 16.

The values of the collapse load multipliers obtained with $L M G C 90$ are always higher than the values obtained with $U D E C$ with a maximal error right above $10 \%$ for the fifth wall, with the exception of the third wall, which can be explained by the difference in the collapse mechanisms. When comparing the full displacement - load factor curves (not represented herein), the results obtained with $L M G C 90$ always seem to indicate that the walls are slightly stiffer than in $U D E C$, except for the stiffness in the elastic range which is identical in both software. This difference in stiffness, which could be a consequence of the distinct definition of the normal stiffness discussed above, could explain why the collapse load multipliers obtained with $L M G C 90$ are always higher than the ones obtained with $U D E C$. This matter will be explored in future works.

The comparison between both software is still limited by the impossibility in $L M G C 90$ to use a contact law between the blocks that includes parameters such as dilatancy or tangential stiffness, which are very common when working with $U D E C$. Inversely, the impossibility to define sharp edges when using $U D E C$ makes it difficult to compare the results obtained with this software with the limit analysis carried out in [8].

\section{CONCLUSION}

Different benchmark problems have been implemented in the open-source DEM software $L M G C 90$ and the results were compared with the literature or with an implementation of the same benchmark problem in the proprietary software $U D E C$. These examples were chosen in order to address some of the most important aspects such as rocking, the joint stiffness and the block imperfections. Overall, the results obtained with the open-source software showed satisfactory resemblance with the literature and with the implementations in UDEC. Familiarisation with the interface of $L M G C 90$ can be time-consuming, and the choice of the tolerance and time step parameters of a simulation requires some experience, but once the user is familiar with the Python interface proposed by $L M G C 90$ and with the structure of the software, it opens up many possibilities for either static or dynamic analyses. The results shown in this paper confirm the applicability and validity of this open-source software in simulating largedisplacement response of masonry structures. Future investigations into the possibilities offered by the $L M G C 90$ software regarding modeling of URM could include in-and-out-of-plane interaction of masonry walls, definition of more parameters such as dilatancy, tangential contact stiffness and damping.

\section{Acknowledgements}

Computational resources have been provided by the supercomputing facilities of the Université catholique de Louvain (CISM/UCL) and the Consortium des Équipements de Calcul Intensif en Fédération Wallonie Bruxelles (CÉCI) funded by the Fond de la Recherche Scientifique de Belgique (F.R.S.-FNRS) under convention 2.5020.11 and by the Walloon Region

\section{REFERENCES}

[1] J. Ahrens, B. Geveci, and C. Law. ParaView: An End-User Tool for Large Data Visualization. Visualization Handbook. 2005. 
[2] A. A. Costa, J. Pirmez, and J. Pacheco de Almeida. Desenvolvimento de curvas de fragilidade à acção sísmica para construções tradicionais de liège, bélgica. In Congresso da Reabilitação, page 11.

[3] H. Crowley. Preliminary european seismic risk results. In European Seismic Risk Workshop, 2019.

[4] H. Crowley, V. Despotaki, D. Rodrigues, V. Silva, D. Toma-Danila, E. Riga, A. Karatzetzou, S. Fotopoulou, Z. Zugic, L. Sousa, S. Ozcebe, and P. Gamba. Exposure model for european seismic risk assessment. Earthquake Spectra, 36(1 suppl):252-273, 2020.

[5] P. A. Cundall. A computer model for simulating progressive large scale movements in blocky rock systems. In Symposium of the International Society for Rock Mechanics, volume II-8. Society for Rock Mechanics (ISRM).

[6] P. A. Cundall. Formulation of a three-dimensional distinct element model-part i. a scheme to detect and represent contacts in a system composed of many polyhedral blocks. International Journal of Rock Mechanics and Mining Sciences Geomechanics Abstracts, 25(3):107-116, 1988.

[7] R. Dimitri, L. De Lorenzis, and G. Zavarise. Numerical study on the dynamic behavior of masonry columns and arches on buttresses with the discrete element method. Engineering Structures, 33(12):3172-3188, 2011.

[8] M. C. Ferris and F. Tin-Loi. Limit analysis of frictional block assemblies as a mathematical program with complementarity constraints. International Journal of Mechanical Sciences, 43(1):209-224, 2001.

[9] A. Isfeld and N. Shrive. Discrete Element Modeling of Stone Masonry Walls With Varying Core Conditions: Prince of Wales Fort Case Study. International Journal of Architectural Heritage, 9(5):564-580, 2015.

[10] G. Lancioni, S. Lenci, Q. Piattoni, and E. Quagliarini. Dynamics and failure mechanisms of ancient masonry churches subjected to seismic actions by using the NSCD method: The case of the medieval church of S. Maria in Portuno. Engineering Structures, 56:1527$1546,2013$.

[11] J. V. Lemos. Discrete element modeling of masonry structures. International Journal of Architectural Heritage, 1(2):190-213, 2007.

[12] F. Perales, F. Dubois, Y. Monerie, B. Piar, and L. Stainier. A nonsmooth contact dynamicsbased multi-domain solver. European Journal of Computational Mechanics, 19(4):389_ 417, 2010.

[13] A. Plumier, C. Doneux, T. Camelbeeck, G. Van Rompaey, D. Jongmans, M. Wathelet, H. Teerlynck, and F. Nguyen. Seismic risk assessment and mitigation for belgium in the frame of eurocode 8 : Final report. Brussels : Federal Science Policy, 2008.

[14] F. Radjai and F. Dubois. Modélisation numérique discrète des matériaux granulaires. Hermes Sciences, Lavoisier, 2010. 
[15] A. Rafiee, M. Vinches, and C. Bohatier. Modelling and analysis of the Nîmes arena and the Arles aqueduct subjected to a seismic loading, using the Non-Smooth Contact Dynamics method. Engineering Structures, 30(12):3457-3467, 2008.

[16] P. Taforel. Apport de la Méthode des Eléments Discrets à la Modélisation des Maçonneries en Contexte Sismique : Vers une Nouvelle Approche Numérique de la Vulnérabilité Sismique. Thesis, 2012. 